\title{
COMPLETE MONOTONICITY AND INEQUALITES INVOLVING GURLAND'S RATIOS OF GAMMA FUNCTIONS
}

\author{
ZHEN-HANG YANG AND SHen-ZHou ZHENG
}

\begin{abstract}
In this paper, by a comparison inequality for an auxiliary function with two parameters, we present necessary and sufficient conditions for four classes of ratios involving gamma function to be logarithmically completely monotonic. These not only greatly generalize and improve certain known results, but also yield many new inequalities for gamma, psi and polygamma functions.
\end{abstract}

Mathematics subject classification (2010): 33B10, 33B15, 33B20, 26A48, $26 \mathrm{D} 05$. equality.

Keywords and phrases: Completely monotonic function, gamma function, polygamma function, in-

\section{REFERENCES}

[1] S. N. Bernstein, Sur les fonctions absolument monotones, Acta Mathematica 52 (1928), 1-66.

[2] D. V. Widder, The Laplace Transform, Princeton University Press, Princeton, 1946.

[3] R. D. Atanassov AND U. V. Tsoukrovski, Some properties of a class of logarithmically completely monotonic functions, Comptes Rendus de l'Académie Bulgare des Sciences (2) 41 (1988), 21-23.

[4] F. QI AND B.-N. GUO, Complete monotonicities of functions involving the gamma and digamma functions, RGMIA Research Report Collection 7 (2004), Art. 8, 63-72, http://rgmia.org/v7n1.php.

[5] ZH.-H. YANG AND J.-F. TIAN, A class of completely mixed monotonic function involving gamma functions with application, Proc. Amer. Math. Soc. 146, 11 (2018), 4707-4721, https://doi.org/10.1090/proc/14199.

[6] M. E. H. Ismail, L. LorCh, AND M. E. Muldoon, Completely monotonic functions associated with the gamma function and its q-analogues, J. Math. Anal. Appl. 116 (1986), 1-9.

[7] J. Bustoz AND M. E. H. Ismail, On gamma function inequalities, Math. Comp. 47 (1986), 659 667.

[8] M. Merkle, Gurland's ratio for the gamma function, Comput. Math. Appl. 49 (2005), 389-406.

[9] F. QI, Q. YANG, AND W. LI, Two logarithmically completely monotonic functions connected with gamma function, Integral Transforms Spec. Funct. (7) 17 (2006), 539-542, http://dx.doi .org/ 10.1080/10652460500422379.

[10] F. QI, Three classes of logarithmically completely monotonic functions involving gamma and psi functions, Integral Transforms Spec. Funct. (7-8) 18 (2007), 503-509, http://dx . doi .org/10.1080/ 10652460701358976.

[11] F. QI AND B.-N. GuO, Wendel-Gautschi-Kershaw's inequalities and sufficient and necessary conditions that a class of functions involving ratio of gamma functions are logarithmically completely monotonic, RGMIA Res. Rep. Coll. 10 (2007), Art. 2; Available online at http://www.staff.vu.edu.au/rgmia/v10n1.asp.

[12] F. QI, A class of logarithmically completely monotonic functions and the best bounds in the first Kershaw's double inequality, J. Comput. Appl. Math. 206 (2007) 1007-1014, http://dx.doi.org/10.1016/j.cam.2006.09.005.

[13] F. QI AND B.-N. GuO, Wendel's and Gautschi's inequalities: Refinements, extensions, and a class of logarithmically completely monotonic functions, Appl. Math. Comput. 205 (2008), 281-290, http://dx.doi.org/10.1016/j.amc.2008.07.005. 
[14] F. QI AND B.-N. GUO, A class of logarithmically completely monotonic functions and the best bounds in the second Kershaw's double inequality, J. Comput. Appl. Math. 212 (2008), 444-456.

[15] F. QI, A class of logarithmically completely monotonic functions and application to the best bounds in the second Gautschi-Kershaw's inequality, J. Comput. Appl. Math. 224 (2009), 538-543.

[16] F. QI, Bounds for the ratio of two gamma functions, J. Inequal. Appl. 2010 (2010), Art. ID 493058, 84 pages, http://dx.doi.org/10.1155/2010/493058.

[17] T. Burić AND N. Elezović, Some completely monotonic functions related to the psi function, Math. Inequal. Appl. 14 (2011), 679-691.

[18] F. QI AND Q.-M. LUO, Bounds for the ratio of two gamma functions: from Wendel's asymptotic relation to Elezović-Giordano-Pečarić's theorem, J. Inequal. Appl. 2013 (2013), Art. 542, http://www. journal of inequalitiesandapplications.com/content/2013/1/542.

[19] F. QI, Bounds for the ratio of two gamma functions: from Gautschi's and Kershaw's inequalities to complete monotonicity, Turkish J. Anal. Number Theory (5) 2 (2014), 152-164, http://dx.doi.org/10.12691/tjant-2-5-1.

[20] ZH.-H. YANG AND Y.-M. CHU, Monotonicity and absolute monotonicity for the two-parameter hyperbolic and trigonometric functions with applications, J. Inequal. Appl. (2016) 2016, Art. 200, http://dx.doi.org/10.1186/s13660-016-1143-8.

[21] ZH.-H. YANG AND SH.-ZH. Zheng, Complete monotonicity involving some ratios of gamma functions, J. Inequal. Appl. (2017) 2017, Art. 255, http://dx.doi.org/10.1186/s13660 $-017-1527-4$.

[22] ZH.-H. YANG AND SH.-ZH. Zheng, Monotonicity of a mean related to polygamma functions with an application, J. Inequal. Appl. (2016) 2016, Art. 216, http://dx.doi.org/10.1186/ s13660-016-1155-4.

[23] Zh.-H. YAng Ang Sh.-ZH. Zheng, The monotonicity and convexity for the ratios of modified Bessel functions of the second kind, Proc. Amer. Math. Soc. (7) 145 (2017), 2943-2958, http://dx.doi.org/10.1090/proc/13522.

[24] ZH.-H. YAng ANG SH.-ZH. Zheng, Monotonicity and convexity of the ratios of the first kind modified Bessel functions and applications, Math. Inequal. Appl. 21 (2018), 107-125, http://dx.doi.org/10.7153/mia-2018-21-09.

[25] T. BURIĆ, N. Elezović, R. ŠImIĆ, Asymptotic expansions of the multiple quotients of gamma functions with applications, Math. Inequal. Appl. 16 (2013), 1159-1170.

[26] D. K. KAZARinoff, On Wallis' formula, The Edinburgh Math. Notes 40 (1956), 19-21.

[27] J. Gurland, An inequality satisfied by the gamma function, Skandinavisk Aktuarietidskrift 39 (1956), 171-172.

[28] Sh. Yu, A. Zhang, H. LI, A review of estimating the shape parameter of generalized Gaussian distribution, J. Comput. Inf. Syst. 21 (2012), 9055-9064, Available at http://www. Jof cis . com.

[29] S. G. MALLAT, A theory of multiresolution signal decomposition: the wavelet representation, IEEE Transactions on Pattern Analysis and Machine Intelligence 11 (1989), 674-693.

[30] K. SHARIFI, A. L. GARCIA, Estimation of shape parameter for generalized Gaussian distribution in subband decompositions of video, IEEE Transactions on Circuits and Systems for Video Technology 5 (1995), 52-56.

[31] CH.-P. Chen AND J. CHOI, Completely monotonic functions related to Gurland's ratio for the gamma function, Math. Inequal. Appl. 20 (2017), 651-659, http://dx.doi.org/10.7153/mia-20-43.

[32] M. Abramowitz And I. A. STegun (Eds), Handbook of Mathematical Functions with Formulas, Graphs, and Mathematical Tables, National Bureau of Standards, Applied Mathematics Series 55, 10th printing, Dover Publications, New York and Washington, 1972.

[33] W. GAUTSCHI, Some elementary inequalities relating to the gamma and incomplete gamma function, J. Math. Phys. 38 (1959), 77-81.

[34] D. Kershaw, Some extensions of W. Gautschi's inequalities for the gamma function, Math. Comp. 41 (1983), 607-611.

[35] H. Alzer, Inequalities for the gamma function, Proc. Amer. Math. Soc. 128 (1999), 141-147.

[36] N. Elezović, C. Giordano, J. PeČARIĆ, The best bounds in Gautschi's inequality, Math. Inequal. Appl. 3 (2000), 239-252.

[37] N. BATIR, Inequalities for the gamma function, Arch. Math. 91 (2008), 554-563, http://dx.doi.org/10.1007/s00013-008-2856-9. 
[38] ZH.-H. YAng AND J. Tian, Monotonicity and sharp inequalities related to gamma function, J. Math. Inequal. 12 (2018), 1-22, http://dx.doi.org/10.7153/jmi-2018-12-01. 